\title{
Systolic Time Intervals in Diabetes
}

\author{
J. Posner ${ }^{1}$, R. Ilya ${ }^{2}$, K. Wanderman ${ }^{2}$ and S. Weitzman ${ }^{3}$ \\ ${ }^{1}$ Division of Medicine, ${ }^{2}$ Cardiology Service, and ${ }^{3}$ Diabetes Clinic and Epidemiology and Health Services Evaluation Unit, \\ Soroka Medical Center, University Center for Health Sciences, Ben-Gurion University of the Negev, Beer Sheva, Israel
}

\begin{abstract}
Summary. The systolic time intervals at rest of 16 Type 1 (insulin-dependent) and 30 Type 2 (non-insulin-dependent) otherwise healthy adult diabetic patients selected from primary health care clinics were compared with those of age- and sexmatched normal subjects by paired analysis. There was no significant difference in prevalence of smoking, body mass index, fasting serum cholesterol or mean blood pressure between the diabetic and control groups. Mean rate-corrected pre-ejection period (diabetic patients: $132.7 \pm 2.1 \mathrm{~ms}$, normal subjects: $134.6 \pm 3.5 \mathrm{~ms}$ ( \pm SEM), left ventricular ejection time (diabetic patients: $413.9 \pm 3.0 \mathrm{~ms}$, normal subjects: $421.5 \pm 4.7 \mathrm{~ms}$ ) electromechanical systole (diabetic patients: $544.9 \pm 2.5 \mathrm{~ms}$, normal subjects: $548.0 \pm 3.5 \mathrm{~ms}$ ) and pre-ejection period/left ventricular ejection time ratio (diabetic pat-
\end{abstract}

ients: $0.36 \pm 0.01$, normal subjects: $0.34 \pm 0.01)$ were not significantly different between the two groups $(p>0.05)$ and systolic time intervals did not correlate with duration of diabetes or type of treatment. Thus, we did not detect subclinical cardiomyopathy in healthy diabetic patients by this technique. However, a statistically significant skew in the distribution of systolic time intervals in the diabetic group $(p<0.025)$ suggests the possibility of an 'at risk' population in which a more sensitive technique might demonstrate impaired ventricular performance.

Key words: Systolic time intervals, diabetic cardiomyopathy, left ventricular performance.
In the past decade the term 'diabetic cardiomyopathy' has gained general acceptance $[1,2]$. While atherosclerotic coronary artery disease is clearly more prevalent and severe in diabetes [3, 4], the Framingham study [5] showed that risk factors for atherosclerosis do not account adequately for the high incidence of heart failure in diabetic patients. Furthermore, diabetic subjects may develop heart failure in the absence of coronary artery disease.

Diabetic cardiomyopathy may have a multifactorial pathogenesis. Microangiopathy $[6,7]$, the hypercoagulable state [8], direct deposition of glycoproteins in the myocardial interstitium [8] and metabolic disturbances [9] may all be involved in the development of morphologic and functional changes in the myocardium.

Non-invasive diagnostic techniques, including echocardiography [10-11], vectorcardiography [12] and the measurement of systolic and diastolic time intervals [11-15] have all been used to demonstrate abnormalities of left ventricular performance in diabetes. Such abnormalities are certainly common in patients with advanced microangiopathy [16] but it is not clear whether subclinical cardiomyopathy is present in patients in good general health, with no clinical evidence of heart disease and without serious diabetic complications. The ability to diagnose the condition before the appearance of overt heart disease becomes of critical importance if the institution of early therapeutic measures for preventing or retarding the progression of the cardiomyopathy is contemplated.

This study reappraises the usefulness of systolic time intervals (STI) in the diagnosis of diabetic cardiomyopathy in diabetic patients without evidence of serious complications of the disease.

\section{Subject and Methods}

Forty-six diabetic patients, 16 Type 1 (insulin-dependent) and 30 Type 2 (non-insulin-dependent) were selected from general practitioners' lists in four health clinics within the catchment area of the Soroka Medical Center in Beer Sheba. Diabetic patients potentially eligible for the study were those diagnosed at least 1 year before entry. Diagnostic criteria were a repeated fasting blood glucose of $\geqslant$ $7.2 \mathrm{mmol} / \mathrm{l}$, or a 2 -h post-prandial value $\geqslant 7.8 \mathrm{mmol} / 1$.

History, physical examination and electrocardiogram were performed to exclude patients with heart or lung disease, endocrine disorders or alcoholism, or receiving drugs which might affect cardiac 
Table 1. Systolic Time Intervals in Diabetic and Normal Subjects

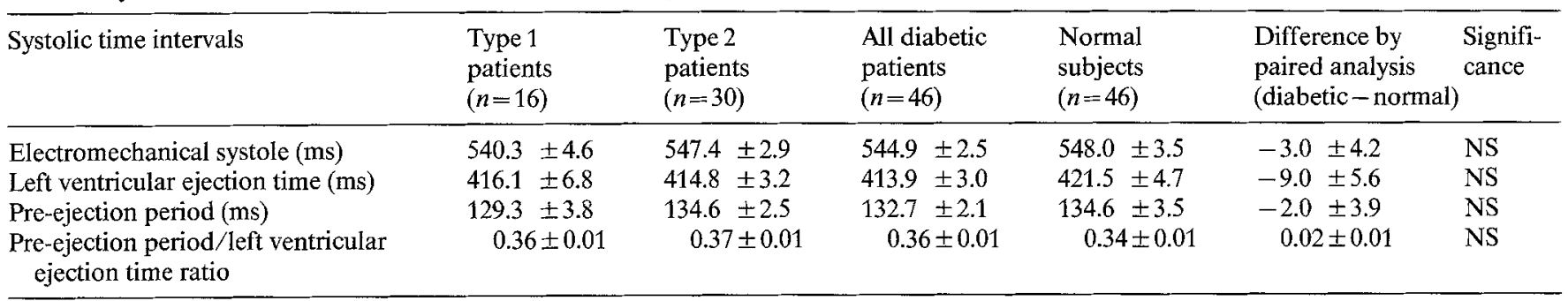

Results expressed as mean $\pm \mathrm{SEM} ; n=$ number of subjects; NS $=$ not significant

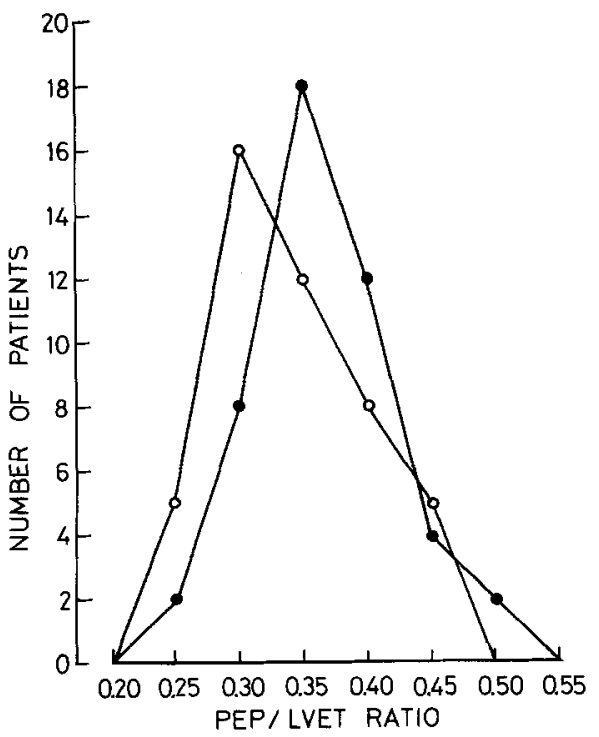

Fig. 1. Distribution of pre-ejection period/left ventricular ejection time (PEP/LVET) ratios of diabetic patients $(-\longrightarrow)$ and normal subjects $(\mathrm{O}-\mathrm{O})$. Each point represents total number of subjects with ratio in the range shown on abscissa

performance. Patients were excluded if they had any abnormalities on auscultation or on the electrocardiogram, a systolic blood pressure above $150 \mathrm{mmHg}$ or diastolic pressure above $95 \mathrm{mmHg}$, renal insufficiency (serum creatinine $>115 \mu \mathrm{mol} / \mathrm{l}$ ) or any evidence of micro- or macrovascular complications.

Healthy normal subjects were selected from the same general practitioners' lists. Each was matched for age and sex with an index case and underwent the same screening procedure to exclude cardiopulmonary disease. A fasting blood giucose of $\leqslant 5.6 \mathrm{mmol} / 1$ was taken as evidence that the subject was not diabetic.

All potential individuals were informed about the nature of the study and were granted the opportunity to decline participation. None of the eligible subjects refused to participate in the study.

Systolic time intervals were recorded with patients at rest in the supine position. Microphones were placed at the pulmonic area and apex to obtain the first high frequency vibrations of the second heart sound and two simultaneous electrocardiogram leads were recorded (a right precordial and a limb lead) so as to define best the earliest deflection of the QRS complex. The carotid pulse was recorded by a funnel pick-up and Statham P23Db transducer (Statham Laboratories, Oxnard, California, USA). A multichannel photographic recording system (Electronics for Medicine VR6, Whiteplains, New York, USA) was used with a paper speed of $100 \mathrm{~mm} / \mathrm{s}$; the mean values of ten cardiac cycles were taken. The intervals measured were total electromechanical systole from the beginning of the QRS complex to the second heart sound (ms), the left ventricular ejection time from the onset of the carotid upstroke to the trough of the carotid incisura (ms), and the pre-ejection period obtained by subtraction of the left ventricular ejection time from the electromechanical systole $(\mathrm{ms})$. Each interval was corrected for rate by the regression equation of Weissler et al. [17] and expressed as index values. The pre-ejection period/left ventricular ejection time ratio was calculated from the uncorrected values as it is known that there is no correlation between this ratio and heart rate.

Results are presented as mean \pm SEM. Student's t-test was used to evaluate the difference of means, and the paired $t$-test for the difference of means in the matched analysis. For comparison of proportions the McNemar test for matched data was used [18]. Paired analysis was performed for comparison of mean systolic time intervals.

There were 21 men and 25 women in each group with five diabetic patients between ages 21 and 30 years, 35 between 31 and 60 years and six over 60 years. The diabetic patients and their age- and sexmatched normal subjects showed no statistically significant differences by paired analysis in the following parameters: body mass in$\operatorname{dex}\left(\frac{\text { weight }}{\text { height }^{2}}\right)$ : diabetic patients $2.8 \pm 0.5$; normal subjects $2.5 \pm 0.3$; prevalence of smoking $30 \%$ and $33 \%$ in diabetic and normal subjects respectively; fasting serum cholesterol $5.8 \pm 0.19 \mathrm{mmol} / 1$ in diabetic patients and $5.8 \pm 0.17 \mathrm{mmol} / 1$ in normal subjects; mean blood pressure ( $\frac{\text { systolic-diastolic }}{3}+$ diastolic) $96 \pm 1.3$ and $95 \pm 1.4 \mathrm{mmHg}$ in diabetic and normal subjects respectively.

The mean duration of diabetes was 8.3 years (range 1-31 years). Twelve patients were diagnosed $<5$ years before testing, 21 between 5 and 10 years and 13 patients had been diabetic for $>10$ years. Fourteen patients were treated with diet alone, 16 with a sulphonylurea agent and 16 with insulin. The mean fasting blood glucose in the diabetic group was $11.4 \pm 0.4 \mathrm{mmol} / \mathrm{l}$; that of the control group was $5.0 \pm 0.1 \mathrm{mmol} / \mathrm{l}$.

\section{Results}

Table 1 shows the mean values of the STI for the two groups and the difference of means by paired analysis. There was no significant difference between the diabetic patients and the control groups for each of the mean intervals or pre-ejection period/left ventricular ejection time ratio. The range of pre-ejection period/left ventricular ejection time ratios was 0.23 to 0.46 for control subjects. However the pre-ejection period/left ventricular ejection ratios fell within the lower tercile $(<0.32)$ in $32.6 \%$ of normal subjects but in only $13 \%$ of the diabetic patients $(p<0.025)$. Conversely, there were more diabetic patients than control subjects with ratios falling in the midtercile $(0.32-0.36)$ although this difference was not significant. There was no difference between the number of diabetic and normal subjects in the upper 
tercile. Figure 1 shows the difference in distribution of STI graphically. This skew of distribution suggests that, with regard to left ventricular performance, the diabetic and control subjects might not be identical populations in spite of the fact that there is no significant difference between mean STI of the two groups.

There was no correlation between STI and age $(r=$ $0.08)$, duration of diabetes $(r=0.16)$ or type of treatment.

\section{Discussion}

We have shown that the STI of otherwise healthy diabetic patients are not significantly different from those of age- and sex-matched normal subjects.

There have been a number of other studies of diabetic cardiomyopathy [10-15] and, in contrast to our results, most demonstrate abnormalities of left ventricular performance. Zoneraich et al. [14] found an increase of $25 \%$ of the pre-ejection period/left ventricular ejection time ratio in 89 diabetic patients compared with 93 control subjects. Since patients with ischaemic heart disease without infarction frequently have entirely normal STI at rest, it was concluded that the abnormal STI reflect impairment of left ventricular performance due to myocardial disease rather than coronary artery disease. Furthermore, the diabetic patients were selected from patients attending a hospital diabetic clinic and are therefore not representative of diabetic patients in the community [19]. In a smaller study, Ahmed et al. [13] compared the STI of 25 diabetic patients without clinically evident heart disease with those of 37 normal subjects and found the pre-ejection period/left ventricular ejection time ratio to be increased in the diabetic patients. The explanation is not readily apparent but again patients were selected from a hospital clinic; no mention is made of the prevalence of diabetic complications. Similarly, D'Elia et al. [20] found evidence of myocardial dysfunction in 8 of 15 patients with diabetic retinopathy and nephropathy but without angiographic evidence of significant coronary artery disease. Shapiro et al. [16] showed a correlation between the severity of microvascular complications and impairment of left ventricular function in 185 diabetic patients without clinical heart disease.

The present study differs in several ways from those discussed. Patients were selected from primary care health clinics. All patients were fully functional and none had evidence of micro- or macrovascular complications. The number treated with diet alone, oral hypoglycaemic agents and insulin were virtually equal. Patients were carefully screened and those with evidence of heart disease, predisposing conditions or receiving medications which might affect cardiac performance were excluded. The control group consisted of age- and sex-matched healthy non-diabetics and paired analysis of the STI was performed. The comparability of the groups is also evident from the almost identical values of the non-matched variables.

The discrepancy between our results and those of previous authors is probably due to these differences in selection of subjects and the analysis of data. Cardiomyopathy was not detected in our diabetic patients. Certainly the absence of other serious complications and hypertension considerably reduces the likelihood of its presence. Nevertheless, the skew of distribution of STI suggests that there may be a subgroup within the diabetic group who may be at risk of developing cardiomyopathy and it is possible that other techniques may be more suited to elicit the defect. If the problem is primarily one of ventricular compliance, then techniques which evaluate diastolic variables may be needed. Both invasive and non-invasive studies appear to support this conclusion. Alternatively, testing of systolic performance after exercise might be informative.

In conclusion, we have not detected subclinical diabetic cardiomyopathy using measurement of systolic time intervals at rest. Further studies utilising other techniques are required to establish whether diabetic cardiomyopathy is present in this population.

Acknowledgements. We wish to thank Drs. A.Kaplan, A.Klein and Y.Roth for their helpful cooperation and Mr. G. Loutaty and Miss M. Kantarovitch for technical assistance. This work was supported by a grant from the Chief Scientist of the Ministry of Health, Israel.

\section{References}

1. Regan TJ, Ahmed SS, Haider B, Lyons MM (1978) The myocardium and its vasculature in diabetes mellitus. Mod Concepts Cardiovas Dis 47: 71-78

2. Shapiro LM (1982) Specific heart disease in diabetes mellitus. $\mathrm{Br}$ Med J 284: 140-141

3. Scott R (1975) Diabetes and the heart. Am Heart J 90: 283-289

4. Weitzman S, Wagner GS, Heiss G, Haney TL, Slome C (1982) Myocardial infarction site and mortality in diabetes. Diabetes Care 5: 31-35

5. Kannel WB, McGee DL (1979) Diabetes and cardiovascular disease. The Framingham study. JAMA 241: 2035-2038

6. Hamby RI, Zoneraich S, Sherman L (1974) Diabetic cardiomyopathy. JAMA 229: 1749-1754

7. Ledet T (1976) Diabetic cardiomyopathy. Acta Path Microbiol Scand 84: $421-428$

8. Regan TJ, Lyons MM, Ahmed SS, Levinson GE, Oldewurtel HA, Ahmad MR, Haider B (1977) Evidence for cardiomyopathy in familial diabetes mellitus. J Clin Invest 60: 885-899

9. Regan TJ, Ettinger PO, Khan MI, Jesrani MU, Lyons MM, Olderwurtel HA, Weber M (1974) Altered myocardial function and metabolism in chronic diabetes mellitus without ischemia in dogs. Circ Res 35: 222-237

10. Sanderson JE, Brown DJ, Rivellese A, Kohner E (1978) Diabetic cardiomyopathy? An echocardiographic study of young diabetics. Br Med J 1: 404-407

11. Shapiro LM, Leatherdale BA, Coyne ME, Fletcher RF, Mackinnon J (1980) Prospective study of heart disease in untreated maturity-onset diabetics. Br Heart J 44: 342-348

12. Reff ER, Riff KM (1974) Abnormalities of myocardial depolarisation in overt, subclinical and prediabetes. A vectorcardiographic study. Diabetes 23: 572--578 
13. Ahmed SS, Jaferi GA, Narang RM, Regan TJ (1975) Preclinical abnormality of left ventricular function in diabetes mellitus. Am Heart J 89: 153-158

14. Zoneraich S, Zoneraich O, Rhee JJ (1977) Left ventricular performance in diabetic patients without clinical heart disease. Chest 72: $748-751$

15. Rynkiewicz A, Semetkowska-Jurkiewicz E, Wyrzykowski B (1980) Systolic and diastolic time intervals in young diabetics. Br Heart $\mathbf{J}$ 44: $280-283$

16. Shapiro LM, Leatherdale BA, Mackinnon J, Fletcher RF (1981) Left ventricular function in diabetes mellitus II: relation between clinical features and left ventricular function. Br Heart $\mathrm{J}$ 45: 129-132

17. Weissler AM, Harris WS, Schoenfeld CD (1968) Systolic time intervals in heart failure in man. Circulation 37: 149-159

18. Anderson S, Auquier A, Hauck WW, Oakes D, Vandaele W and Weisberg HI (1980) Statistical methods for comparative studies: techniques for bias reduction. John Wiley, New York, p 94
19. Shapiro LM, Howat P, Calter MM (1981) Left ventricular function in diabetes mellitus $\mathrm{I}$ : methodology, and prevalence and spectrum of abnormalities. Br Heart J 45: 122-128

20. D'Elia JA, Weinrauch LA, Healy RW, Libertino JA, Bradley RF, Leland OS (1979) Myocardial dysfunction without coronary artery disease in diabetic renal failure. Am J Cardiol 43: 193-199

Received: 24 May 1982

and in revised form: 2 December 1982

Dr. S. Weitzman

Diabetes Clinic

Epidemiology and Health Services Evaluation Unit

Soroka Medical Center

Ben-Gurion University of the Negev

P.O. B. 653

Beer Sheba 84120

Israel 